\title{
Enablers and Barriers to Successful Implementation of Cooperative Learning through Professional Development
}

\author{
Mohamed Alansari ${ }^{1, *}$ and Christine Margaret Rubie-Davies ${ }^{2}$ \\ 1 New Zealand Council for Educational Research, Wellington 6011, New Zealand \\ 2 Faculty of Education and Social Work, The University of Auckland, Auckland 1010, New Zealand; \\ c.rubie@auckland.ac.nz \\ * Correspondence: mohamed.alansari@nzcer.org.nz
}

Citation: Alansari, M.; Rubie-Davies,

C.M. Enablers and Barriers to

Successful Implementation of Cooperative Learning through Professional Development. Educ. Sci. 2021, 11, 312. https://doi.org/ 10.3390/educsci11070312

Academic Editor: Robyn M. Gillies

Received: 4 May 2021

Accepted: 11 June 2021

Published: 23 June 2021

Publisher's Note: MDPI stays neutral with regard to jurisdictional claims in published maps and institutional affiliations.

\begin{abstract}
Literature shows cooperative learning has positive benefits for students' learning and social outcomes. Even though cooperative learning studies have been conducted in all areas of the curriculum, few studies have investigated whether there are similar effects for students across several curriculum areas or age groups. Moreover, less attention has been given to how professional learning and development (PLD) opportunities can contribute to changes in instructional practice. We illustrate how research on cooperative learning can be translated into practice, through a one-year University-School partnership. The current study is focused on our PLD work in one large private school based in New Zealand. Analysis of school data (quantitative student data and qualitative teacher data) indicated that, by the end of the school year, students reported experiencing more cooperative learning opportunities in their classes. Teachers believed that the PLD supported change in their practice and noted positive changes in student engagement. Analysis of student data also revealed differential outcomes by subject and age group. Overall, our study showed that PLD opportunities can contribute to the successful implementation of cooperative learning.
\end{abstract}

Keywords: cooperative learning; professional learning and development; grouping; group work

\section{Introduction}

Cooperative learning involves students in small groups working and learning together in a supportive manner to complete an assigned task [1]. It has been implemented successfully across a wide range of curriculum areas and with students at all levels of schooling. Cooperative learning has also been shown to be effective across a wide range of tasks designed to develop higher levels of conceptual understanding and critical thinking $[2,3]$. Hence, because cooperative learning has consistently been shown to improve student learning and social outcomes, interest in implementing this strategy has continued to increase since the 1980s [4]. Nevertheless, researchers often introduce interventions over a short period, in one curriculum area and with one age level $[5,6]$. Further, many interventions do not take place within an authentic classroom context. As a result, when the intervention ends, teachers are not equipped to incorporate cooperative learning across a range of curriculum areas and throughout the academic year [7], and so may revert to a more didactic form of teaching. Further, teachers are often not involved in the design of the tasks or how they will be implemented [8]. This can mean that they are not well equipped to carry on with the intervention once the research project ends.

The current project was designed to address some of these gaps in the literature. First, rather than focusing on one curriculum area, our intervention was implemented across four core areas: English, mathematics, science and social sciences. Second, both elementary and middle school students were involved, rather than there being a focus on one age group. Third, the professional development that comprised the intervention took place over four school terms (40 weeks, a full academic year in New Zealand), whereby the staff of one school attended a series of workshops with the researchers, coupled with regular meetings 
with the leadership team and Deputy Principal to discuss progress, successes and barriers, and to plan future sessions. Finally, a key component of the professional development involved the teachers planning cooperative learning tasks together for their students that they would implement. This planning took place with the researchers on hand to monitor the alignment of cooperative learning principles with what was to be instituted. Hence, the researchers worked cooperatively with the school leaders and teaching staff to help them monitor and implement cooperative learning tasks into their teaching.

Cooperative learning is described [9-11] as being comprised of certain key components if students are to benefit from being involved. First, students need to be positively interdependent. Second, students need to be seated in a manner which facilitates face-toface interaction so they can see each other and read each other's body language. Third, students, both individually and collectively, need to be responsible and accountable for particular aspects of the task. Fourth, the task should encourage students to develop and demonstrate positive teamwork skills. Fifth, there should be equal participation of group members accompanied by helpful, supportive behavior among the group. Sixth, regular reflection on the group's progress in developing cooperative learning skills is useful so that students understand which skills they have mastered and where they still need to put in additional effort [7].

There are additional organizational and structural arrangements that have been shown to contribute to positive cooperative learning experiences for students [12]. These include having no more than four of five students in each group and beginning with two-three students working together. Further, maintaining stable groups for one term (approximately 10 weeks) enables students to develop positive relationships which include trust, respect and sensitivity to others' views. When groups are stable for an extended period, this also builds confidence among all members and encourages them to contribute. Baines and colleagues [12] also recommend using mixed ability groups but putting high and middle achievers together and low and middle together in other groups to avoid frustration. In addition, they recommend including boys and girls in each group.

For the above criteria to be fulfilled, teachers play a critical role. It is mainly teachers who will decide on the group task and the tasks need to be appropriate for group work, but the tasks also need to encourage the development of teamwork skills and positive interdependence. Such tasks are likely to have multiple open-ended solutions that encourage discussion. Students also need a clear understanding of what is required from the task and how they are expected to work together [4]. Further, students may be unused to working cooperatively in groups and so will need explicit training to develop positive and supportive teamwork skills [7]. This means that students need to be taught the prosocial and group work skills necessary to form positive interactions with their peers to cooperatively engage in the task at hand. It is also important that teachers monitor their groups closely when they are interacting. Teachers can ask thought-provoking questions, ask for elaborations and prompt students to provide explanations and justifications $[4,13]$. In short, if students are to successfully exchange ideas, speculate about possible conclusions, explain or justify their reasoning or make inferences, they need to be taught these new ways of working together. Given that students are engaged in high-level interactions that will enhance their thinking and learning, as well as in advanced groupwork skills, the training that teachers implement is likely to take time. Students cannot be expected to sit in groups and immediately work as a group $[2,7,12,14]$. This is one reason why gradual and extended implementation of cooperative learning is likely to be more effective than a brief intervention. In setting up a cooperative learning classroom, time to effectively train students in how to work together needs to be set aside. Endorsing this point, researchers $[7,15]$ have shown that when students are taught how to engage in group learning and support, they exhibit higher level thinking, reasoning and academic performance than students who have not been trained. For similar reasons, it is also beneficial to allow time at the end of each cooperative learning session to have students reflect on their mastery of the skills required. This enables 
students to think about how well they have interacted, the degree to which all students were involved, and how they are moving to positive interdependence.

There is now a vast literature that attests to the positive benefits of cooperative learning for student outcomes. In addition, a number of meta-analyses [16-19] have further endorsed the advantages of this form of structuring the learning environment. In an early meta-analysis of 122 studies, Johnson and colleagues [16] reported that cooperative learning resulted in better achievement outcomes than either individual efforts or group competition. Additionally, their meta-analysis incorporated studies in several curriculum areas (literacy, mathematics, science, social studies and physical education) and at all schooling levels. There were advantages for students in cooperative learning groups for any activities that involved higher level and logical thinking, problem solving and drawing conclusions.

Slavin [19] compared students at elementary and secondary schools, in 60 studies who were either in control or cooperative learning groups. He showed that in most of the studies $(72 \%)$, students achieved better academic results on the same task when they were working in cooperative groups than if they were in a control group.

Later Johnson and Johnson [20] compared outcomes across 117 studies when students were in cooperative groups, competitive groups or working alone. They found large, positive differences for cooperative learning compared with the other two learning structures across a wide range of variables: academic performance, social support, self-esteem, perspective-taking and handling controversy. Hence, this meta-analysis also endorsed the benefits for students of cooperative learning.

A more recent meta-analysis [18] of 148 studies again compared differences in achievement outcomes for cooperative learning versus competitive or individual learning structures. However, the authors also investigated the effects on peer relationships. Again, they reported high levels of achievement when students cooperated in groups rather than when they competed or worked alone but in addition, they were also able to show that peer relationships were more positive with cooperative learning than for the other two learning structures. Overall, these meta-analyses have indicated that there are clear achievement and social benefits for students when they work in cooperative groups compared with other ways of organizing students.

Even though cooperative learning studies have been conducted in all areas of the curriculum [16], few studies have investigated whether there are effects for the same students across several curriculum areas. This is important because some curriculum areas may be more conducive than others to enhancing student outcomes through the use of cooperative learning. For example, there have been several studies in the past two decades that have investigated the effects of cooperative learning on science outcomes [21-24]. Other studies have investigated effects in mathematics [25-27]. Far fewer studies have investigated effects in literacy (see study Marcos and colleagues [8] for a recent exception) and social studies [28]. Even though, the studies of cooperative learning in science and mathematics consistently report positive benefits for students, the recent intervention study of Wanzek and colleagues [28] in social studies is less convincing. In that study, students in the intervention group produced more accurate ideas in an essay and showed small positive differences for providing supporting details in their essay compared with the control group, but they did not show any gains when assessed on a multiple-choice test of content knowledge. However, one key aspect of cooperative learning activities is that they are designed to improve student social outcomes, for example, peer relationships, peer support, positive interdependence. Even though most studies report student academic outcomes, few investigate student perceptions of the cooperative learning activities or changed learning environment that results.

The current study took place in a private boys' school and included students from both Years 5 and 6 (Grades 4 and 5) and Years 7 and 8 (Grades 6 and 7). The school had a very traditional approach to teaching, but the management team were interested in whether or not the introduction of cooperative learning would lead to improved student-teacher relationships and student enjoyment of school. They were also interested in whether 
teachers would implement cooperative group work during and following the intervention. The study involved primary students (Years 5 and 6) whose teachers were responsible for all curriculum areas and also middle school students (Years 7-8) who had subject teachers for each different curriculum area. The researchers used the work of Blatchford and colleagues $[2,7,12,14]$ as a basis for the intervention and paid close attention to the guidelines offered in the handbook that arose from the, Social and Pedagogical Research into Grouping (SPRinG project; see [12]), a large cooperative group project conducted in the UK. This handbook clearly outlines the steps needed for effective implementation of cooperative learning activities, including both the teacher and student learning that needs to occur.

The research questions pertaining to this study were:

1. Is the introduction of whole-school professional development on cooperative learning associated with changes in classroom practices (teacher support and group work behaviors)?

2. Do students report greater levels of teacher support and more group work in math, science, English and social sciences from the beginning to the end of the year of the implementation?

3. Do student reports of teacher support and group work differ by age group from the beginning to the end of the year of the implementation?

\section{Materials and Methods}

This study was based on a partnership between the authors, who provided the teacher professional learning and development (PLD) and a single-sex full primary (Years 1-8; ages 5-12), private school located in a high socioeconomic area within New Zealand. All teachers at the school undertook a whole-year of professional development with the authors (described later) and were asked to implement group work and cooperative learning strategies 2-3 times per term to begin with, then increase that every term. A product of this partnership was a survey, co-developed with the school leaders and authors to measure student perceptions of specific teaching and learning priorities within the school related to cooperative learning. The school was interested in whether students reported greater teacher support (as a byproduct of working in groups) and increased opportunities to work in groups over the year of the intervention. Anonymized student data and teacher feedback on the PLD were provided to the authors, following ethical and school permission to use these data for research purposes. Since data were gathered before and after the PLD had begun, and given our partnership was centered around a whole-school professional development program, this led the research design to form a natural quasi-experimental study whereby pre- and post- data were gathered on student experiences following planned changes in teaching practice. Hence, we could compare beginning-year student reports related to group work with end-of-year reports after they had been involved in group work for one school year.

\subsection{Participants}

A total of 599 and 437 students, respectively, completed the student surveys in Terms 1 and 4 (i.e., at the beginning and end of the academic year, corresponding to before and after the school-wide professional development). The school gathered data from elementary (Years 5-6, approximately 9-10 years old) and middle (Years 7-8, approximately $11-12$ years old) school students across all curriculum areas. We have, however, focused our analyses on the four core curriculum areas (English, Social Science, Science and Mathematics). We acknowledge the drop in student responses at Term 4, which are likely due to students changing schools or being absent on the day of the survey administration. Table 1 (below) shows the breakdown of the students by year level and curriculum area. 
Table 1. Breakdown of students by year level and curriculum area.

\begin{tabular}{cccccc}
\hline Year Level & & $\begin{array}{c}\text { Beginning Year Respondents } \\
\text { (Before PLD) }\end{array}$ & \multicolumn{2}{c}{$\begin{array}{c}\text { End-of-Year Respondents } \\
\text { (After PLD) }\end{array}$} \\
\hline & & $\boldsymbol{n}$ & $\mathbf{\%}$ & $\boldsymbol{n}$ & $\mathbf{\%}$ \\
\hline Year 5 & & 68 & 11.4 & 62 & 14.2 \\
Year 6 & & 23 & 11.5 & 74 & 16.9 \\
Year 7 & & 38.9 & 166 & 38.0 \\
Year 8 & & 38.2 & 135 & 30.9 \\
Years 5 and 6 & All subjects & 137 & 22.9 & 136 & 31.1 \\
Years 7 and 8 & English & 122 & 20.4 & 68 & 15.6 \\
& Social & 87 & 14.5 & 48 & 11.0 \\
& Sciences & 113 & 18.9 & 94 & 21.5 \\
& Science & 140 & 23.4 & 91 & 20.8 \\
Total & Mathematics & 599 & 100 & 437 & 100 \\
\hline
\end{tabular}

\subsection{Measures}

Below we report on our findings from the student survey data and teacher feedback. As noted earlier, the student survey was co-designed to ensure that the items reflected the school's teaching and learning priorities for the year which were to increase teacher support of students and to increase teacher use of cooperative learning in their classroom programs. We wanted to ensure that the school could use the information from the survey items for their ongoing professional development. This meant that the adoption of existing or pre-established scales was not possible because the school wanted input into the items that constituted the survey.

The survey gathered anonymized student data on specific learning experiences during the year. Students were asked to indicate their levels of agreement versus disagreement on a 5 -point Likert scale $(1=$ strongly disagree, $2=$ disagree, $3=$ neither agree or disagree, $4=$ agree, 5 = strongly agree) on nine items. For example, "My teacher gives me opportunities to work in a small group" and "I find the group learning tasks enjoyable" (all items are presented in Figure 1 within Section 3).

In addition, teachers were asked to provide anonymous feedback online following Term 4, on their thoughts on the PLD and whether they thought it had made a difference to their practice. It must be noted here that gathering of student achievement data was not possible in this study, as different groups of teachers indicated that they used different achievement tests for different subjects, some of which were not standardized. This meant that baseline achievement data would not have been comparable across the subjects and year levels. Therefore, we opted for a school-wide student survey and teacher feedback as our proxies for successful implementation-or at least trialing - of cooperative learning strategies and group work skills in the classroom. Feedback from school leaders also suggested that data from student surveys would be beneficial to inform future school-wide teaching and learning priorities.

\subsection{Professional Learning Development and Data Collection Procedures}

We were approached by the school at the end of one academic year to form a partnership focused around providing support with implementing cooperative learning and group work skills as a school-wide focus for the following year's teaching and learning priorities. We spent time meeting with the school's teaching staff and senior leadership team in order to develop our relationships with the school and to understand their needs. We also wanted to mutually agree on potential measures that were specific to the school's needs but would also allow us to explore changes over time in student attitudes towards (and perceptions of) cooperative learning and group work skills, and to include a teacher measure to determine if PLD was effective in shifting teachers' practice. 
During our initial conversations with the school and curriculum leaders, we discovered that most teachers did not typically use cooperative learning strategies in their classes. We also discovered that some teaching departments—-particularly mathematics-were resistant to group work learning strategies and mixed ability grouping, as they employed ability grouping instead. This informed our planning of the PLD workshops where we incorporated, for example, a comprehensive range of literature showing the potential positive effects of cooperative learning strategies and teaching group work skills, compared with the negligible and often negative effects of ability grouping on student learning outcomes [29]. We also discovered that the school provided few opportunities for teachers to talk about their teaching practice in their subject departments or year-level groups. Therefore, in our workshops, we incorporated examples of cooperative learning strategies across curricular areas and year levels, and, later in the year, we invited teachers from different departments to share their teaching practice and how they had tried to incorporate cooperative learning strategies into their lesson plans and teaching practice.

The main component of the PLD consisted of a series of eight workshops (both with the senior leadership team and teaching staff) across the academic year. In addition, the first author met monthly with the Deputy Principal about progress and any challenges staff were facing and provided individual teacher support when requested. It was important to involve the senior leadership team in the PLD program to encourage their buy-in, involvement, and on-going support of teachers' change in practice within their departments and year-level groups. We were available both in-person and online to provide one-on-one support and to disseminate research resources or help with any difficulties that teachers or departments encountered.

As part of the school's teaching inquiry and review of practice, teachers were expected to be familiar with the research supporting cooperative grouping and to share examples and reflections from their own practice. We factored that into our professional learning and development workshops and allowed opportunities for teachers to present their ideas and ways in which they had incorporated cooperative learning and group work skills into their teaching during Terms 2 and 3 (April-June and July-September) when we were delivering the PLD. This meant that teachers were involved in each other's professional development and had opportunities to learn more about how others had incorporated cooperative learning within their curriculum area and for their group of students. Running a workshop with the school once or twice a term meant that teachers were also reminded of, and exposed to, the content of the PLD on numerous occasions, and were given multiple opportunities to clarify understandings or acquire feedback on how to fine-tune their cooperative learning practices and implementation of group work skills. As authors and PLD providers, we held regular meetings together and met with the Deputy Principal for debriefing and reflection sessions, following each workshop.

School leaders disseminated the student survey in both Terms 1 and 4 . Students in this school are used to providing input into school and classroom processes so completion of a survey was not a new experience. The same survey was used with students of all ages, and we ensured that the wording was simple and easy to understand by primary-aged children. We provided the teachers with specific instructions to ensure reliable and consistent data collection protocols, including a spreadsheet into which the data would be entered at both Terms 1 and 4. All students completed their surveys online, and we were provided with a collated anonymized dataset for analysis. Following Term 4, teachers provided their anonymous feedback on the PLD electronically to the school leaders who were interested in the teacher-perceived value of the PLD and whether the PLD had resulted in any changes to their practice. Teacher feedback was in the form of open-ended responses. This anonymous data was then forwarded to the authors. Table 2 below summarizes the main activities undertaken throughout the year in partnership with the school. 
Table 2. Professional learning and development activities and data gathering procedures.

\begin{tabular}{|c|c|}
\hline Academic School Year & Main Activities \\
\hline Term 1 (February-April) & $\begin{array}{l}\text { - Initial } 3 \text { meetings with the school's senior leadership team. } \\
\text { - Two initial workshops with the school's senior leadership team on cooperative learning } \\
\text { and group work skills. } \\
\text { - } \quad \text { Co-development and online distribution of student surveys. } \\
\text { - } \quad \text { ofl-staff workshop on cooperative learning and group work skills (theory and examples } \\
\text { - Staff planning for change in practice and setting the year's teaching and learning priorities. }\end{array}$ \\
\hline Term 2 (May-July) & $\begin{array}{l}\text { - } \quad \text { Staff implement cooperative learning and group work skills minimum 2-3 times per term. } \\
\text { - } \quad \text { wwo whole staff workshops on cooperative learning and group work skills (theory and } \\
\text { - All-staff reflection on adapted teaching practice, sharing examples from their practice and } \\
\text { planning for "fine-tuning". } \\
\text { - Middle leaders facilitate discussions within Year/Department/Syndicate on staff use of } \\
\text { cooperative learning group work in their classes. } \\
\text { - } \quad \text { Peer observations and feedback*. } \\
\text { - to teachers. } \\
\text { Ongoing monthly meetings with the senior leadership team. }\end{array}$ \\
\hline Term 3 (July-October) & $\begin{array}{l}\text { - Staff implementing cooperative learning and group work skills 2-3 times per } \\
\text { - term minimum. } \\
\text { Two all-staff workshops on cooperative learning and group work skills (re-visiting theory } \\
\text { and examples of practice). } \\
\text { - Whole staff reflection on adapted teaching practice, sharing examples from their practice } \\
\text { and planning for "fine-tuning". } \\
\text { - Peer observations and feedback. } \\
\text { - Authors available for one-on-one or group support and disseminating online resources } \\
\text { to teachers. } \\
\text { - Middle leaders facilitate discussions within Year/Department/Syndicate on staff use of } \\
\text { - Oooperative learning and group work in their classes. } \\
\text { Ongoing monthly meetings with the senior leadership team. }\end{array}$ \\
\hline Term 4 (October-December) & $\begin{array}{l}\text { - All-staff workshop and reflection on adapted teaching practice, sharing examples from } \\
\text { their practice. } \\
\text { Middle leaders facilitate discussions within Year/Department/Syndicate on staff use of } \\
\text { - } \quad \text { Online distribution of student surveys. } \\
\text { - } \quad \text { Gathering staff electronic feedback on the PLD. }\end{array}$ \\
\hline
\end{tabular}

Note. * It was common practice for teachers at the school to conduct peer observations, so we incorporated that into our PLD and asked that they focus on observing their peers using cooperative learning tasks in their classes and provide feedback on successes and areas for development.

\subsection{Data Analysis Plan}

Preliminary checks of the data were conducted to ensure reliability and validity prior to the main analyses. Given the student survey was developed by the school in consultation with us, a factor analysis was necessary to investigate potential underlying patterns in student responses. Since previous studies have found varying effects across subjects and/or year levels, differences in student responses were analyzed separately for Year 5-6 students in homeroom classes, and for Year 7-8 students in different subjects, using analysis of variance tests and Bonferroni correction to account for possible inflations in Type-1 Error. $F$-tests and associated $p$-values were used to detect statistically significant differences that were not due to chance, whereas eta-squared was used as a measure of effect size to check whether the magnitude of differences was practically significant or meaningful (0.01, 0.06 and 0.14 denote small, moderate and large effects, respectively, see Pallant [30]). In addition, we examined whether there were overall changes in student reports of their teachers' support and group work behaviors. We were particularly interested in whether 
students were provided with more opportunities to work in groups following our PLD. Therefore, analysis of the responses to this item is presented below. All quantitative analyses were conducted using IBM SPSS Statistics v27. Teacher feedback was gathered following Term 4, and a reflexive thematic analysis [31] was conducted to look for overall themes in how staff perceived the PLD.

\section{Results}

\subsection{Preliminary Analyses}

We hypothesized that responses to the 9-item student survey were likely to yield a single-factor solution (grouping all items into one overall 'teaching and learning' factor) or a two-factor solution that separated out the items specifically pertaining to group work behaviors from those pertaining to the personal and academic support provided by teachers (see Figure 1 below).

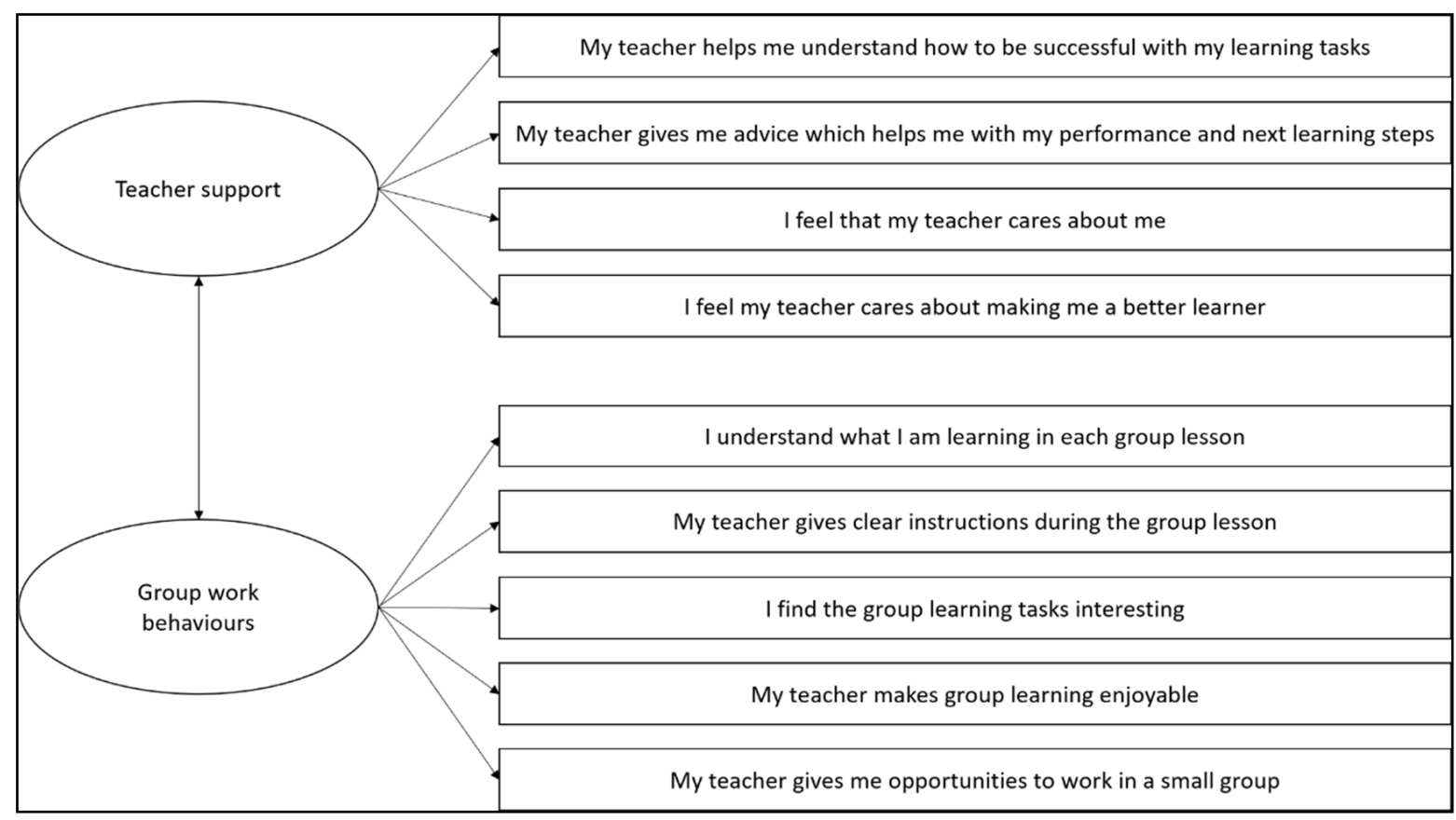

Figure 1. Conceptual diagram showing the hypothesized 2-factor model.

We ran a confirmatory factor analysis (CFA) with maximum likelihood estimation to explore the factorial reliability of a two-factor solution on the full cohort, being our theory-driven model, versus a single factor solution being the alternative or competing model [32]. An examination of the model fit indices suggested that our hypothesized two-factor model (Chi-square $/ \mathrm{df}=4.22, p<0.05 ; \mathrm{CFI}=0.97 ; \mathrm{TLI}=0.96$; RMSEA $=0.056$; $\mathrm{SRMR}=0.03$ ) was superior to a single factor model (Chi-Square $/ \mathrm{df}=7.37, p<0.05$; $\mathrm{CFI}=0.90 ; \mathrm{TLI}=0.87 ; \mathrm{RMSEA}=0.103 ; \mathrm{SRMR}=0.05)$ and was deemed acceptable [33] Figure 2 shows the two-factor measurement model along with standardized estimates using the full sample (i.e., the Terms 1 and 4 combined data; $n=1036$ ). All items loaded significantly onto their respective factors (standardized regression estimates $>0.30$ for all items, $p<0.001)$, with the two factors beings positively and strongly correlated $(r=0.87$, $p<0.001)$. 


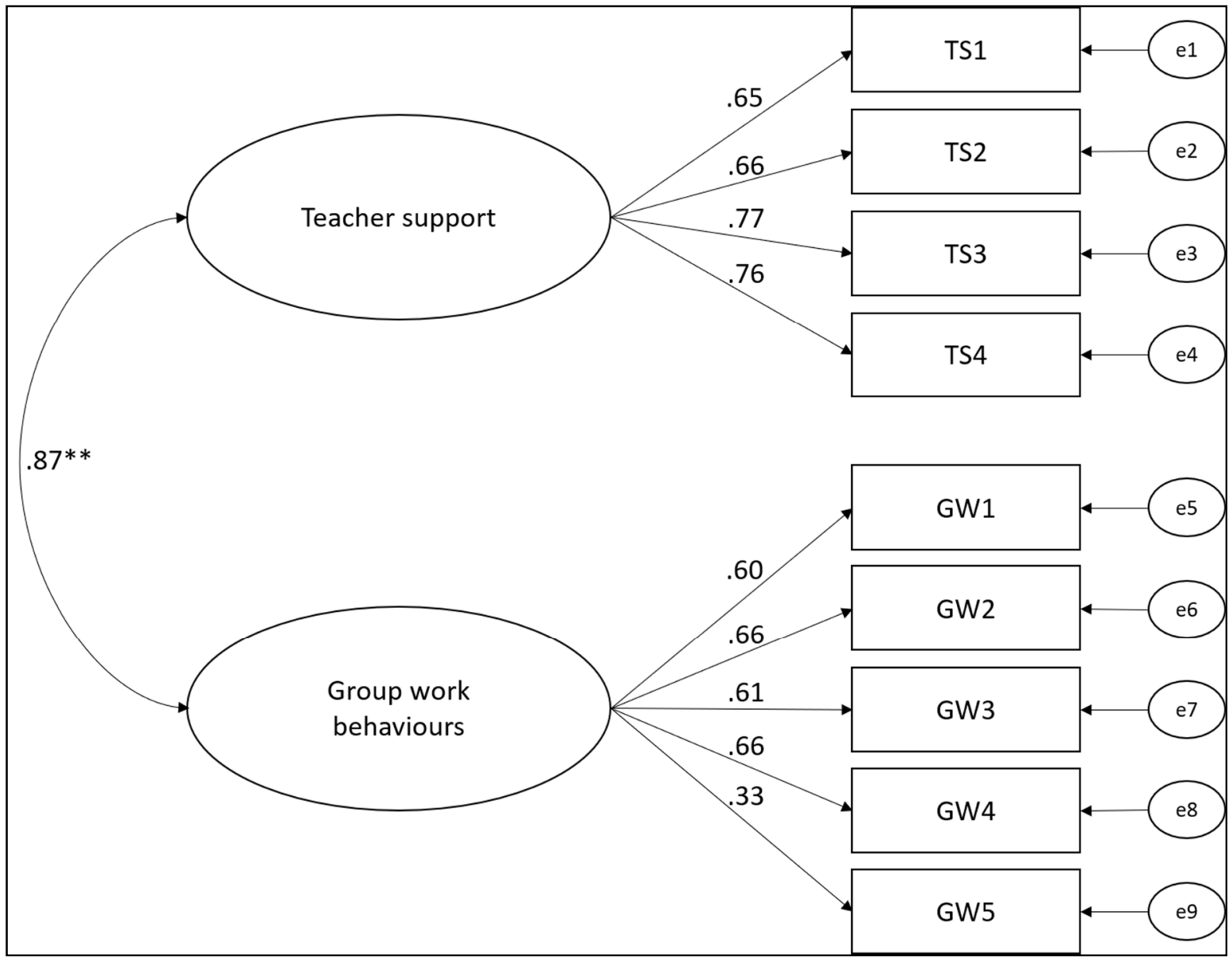

Figure 2. Standardized estimates of the two-factor measurement model using the full sample.

Having established that a two-factor model could be used with the full cohort of students, measurement invariance testing was conducted to ensure that the factor structure was equivalent across cohorts (i.e., those who completed the survey at Terms 1 and 4). To do so, changes in model fit indices (specifically CFI, SRMR and RMSEA) were inspected, and are presented below in Table 3.

Table 3. Measurement invariance testing of the two-factor solution by cohort.

\begin{tabular}{ccccccccc}
\hline & CFI & SRMR & RMSEA & $\mid \boldsymbol{\Delta}$ | CFI & I $\mathbf{|}$ | SRMR & I $\Delta$ | RMSEA & Decision \\
\hline Configural invariance & 0.966 & 0.039 & 0.046 & - & - & - & Accept \\
Metric invariance & 0.967 & 0.040 & 0.042 & 0.001 & 0.001 & 0.004 & Accept \\
Scalar invariance & 0.968 & 0.040 & 0.041 & 0.001 & 0.000 & 0.001 & Accept \\
Residual invariance & 0.966 & 0.041 & 0.038 & 0.002 & 0.001 & 0.003 & Accept \\
\hline
\end{tabular}

As can be seen, given that changes in CFI, SRMR and RMSEA were less than 0.01 [34-36] across the four levels of invariance $(|\Delta|<0.004$ for all three indices), this suggests residual or strict invariance was achieved, and that the same two-factor structure could be used for either cohort of students. We therefore proceeded to calculating mean scores for the two factors for both cohorts at Terms 1 and 4, as shown in Table 4 below. 
Table 4. Means and standard deviations of the two factors overall and by subject.

\begin{tabular}{ccccc}
\hline & \multicolumn{2}{c}{ Teacher Support } & \multicolumn{2}{c}{ Group Work } \\
\hline & Term 1 & Term 4 & Term 1 & Term 4 \\
Homeroom (all curriculum areas) & $M(S D)$ & $M(S D)$ & $M(S D)$ & $M(S D)$ \\
English & $4.07(0.70)$ & $4.06(0.81)$ & $3.79(0.63)$ & $3.83(0.73)$ \\
Social Sciences & $4.27(0.68)$ & $4.37(0.57)$ & $3.95(0.66)$ & $4.28(0.52)$ \\
Science & $4.14(0.75)$ & $4.30(0.58)$ & $4.02(0.61)$ & $4.04(0.59)$ \\
Math & $3.95(0.76)$ & $3.92(0.71)$ & $4.07(0.71)$ & $3.91(0.62)$ \\
Overall & $4.33(0.61)$ & $4.31(0.63)$ & $4.02(0.64)$ & $4.02(0.63)$ \\
\hline
\end{tabular}

Note. Cronbach's alpha $>0.70$ for all subgroups and overall factor scores, at both time points. Note II. Skewness and kurtosis values were inspected, and no departures from normality assumptions were found.

\subsection{Differences in Student Ratings}

Multiple analysis of variance (MANOVA) testing was conducted to assess whether there were statistically significant changes in student perceptions of teacher levels of support and their group work behaviors over time, and whether there was a significant interaction between those and the subject in which cooperative learning was introduced, as well as the age group of the students. Furthermore, we were particularly interested in whether the PLD had influenced the extent to which students were given more opportunities to work cooperatively in small groups. This was a central focus of the PLD. Therefore, we ran additional analyses on student responses to that particular item.

Overall, we found statistically significant differences in student ratings between Terms 1 and $4(F(3,1024)=22.03, p<0.001$; Wilks' Lambda $=0.94$, partial eta-squared $=0.06)$, by subject $(F(12,2710)=9.69, p<0.001$; Wilks' Lambda $=0.90$, partial eta-squared $=0.04)$, as well as a statistically significant interaction between those $(F(12,2710)=2.62, p<0.01$; Wilks' Lambda $=0.97$, partial eta-squared $=0.01$ ). Additionally, we found statistically significant differences in student ratings by age group $(F(3,1030)=7.99, p<0.001$; Wilks' Lambda $=0.98$, partial eta-squared $=0.02$ ), but no statistically significant interaction effects.

First, we found statistically significant differences in the extent to which students reported that they were provided with more opportunities to work cooperatively in small groups $(F(1,1026)=45.82, p<0.001$; partial eta-squared $=0.04)$. That is, overall, significantly more students in Term 4 reported getting opportunities to work in small groups than in Term 1.

There were also statistically significant differences in student ratings by subject. Students who undertook cooperative learning in different subject areas reported significantly different levels of teacher support $(F(4,1026)=12.30, p<0.001$; partial eta-squared $=0.05)$, group work behaviors $(F(4,1026)=7.18, p<0.001$; partial eta-squared $=0.03)$ and opportunities to work in small groups $(F(4,1026)=10.43$, $p<0.001$; partial eta-squared $=0.04)$. Post-hoc Tukey tests revealed that students in science and homeroom classes (where teachers taught all curriculum areas) reported significantly lower levels of teacher support and group work behaviors, whereas students in English classes reported higher levels. Finally, students in Mathematics and Homeroom classes reported experiencing significantly fewer opportunities to work in small groups. Interestingly, although students in science classes reported significantly lower levels of teacher support and group work behaviors, those students reported getting the most opportunities to work in small groups.

Moreover, we found a statistically significant interaction between cohorts (i.e., beginning and end-of-year students) and subjects for group work behaviors $(F(4,1026)=3.47$, $p<0.01$; partial eta-squared $=0.01$ ) and getting opportunities to work cooperatively in small groups $(F(4,1026)=4.39, p<0.01$; partial eta-squared $=0.02)$, but not for teacher support. These interactions are presented in Figures 3 and 4 below. As shown in Figure 3, students in English classes reported significantly more positive ratings of group work behaviors than any other group by Term 4 , and those in science were the only group 
whose ratings dropped by Term 4 . Further, Figure 4 depicts student perceptions of the opportunities they were given to work cooperatively in small groups. Even though all group ratings increased by Term 4, students in English classes had the largest increase, whereas those in Science and Mathematics classes had the smallest increase.

Lastly, we found a statistically significant difference in student ratings by age group for teacher support $(F(1,1032)=6.81, p<0.01$; partial eta-squared $=0.01)$, group work behaviors $(F(1,1032)=23.64, p<0.001$; partial eta-squared $=0.02)$ and being given opportunities to work cooperatively in small groups $(F(1,1032)=10.35, p<0.01$; partial eta-squared $=0.01$ ). That is, younger students (aged 9-10 years) reported receiving less teacher support, engaging in fewer group work behaviors and getting fewer opportunities to work cooperatively in small groups than older students (aged 11-12 years). The finding of no statistically significant interaction between terms and student ratings suggests that these differences remained similar across the whole year.

Overall, student ratings of group work behaviors and opportunities to work in small groups increased over the year, particularly in English. However, few or no changes were evident in ratings of teacher support and by students in science and mathematics classes. No changes were evident for younger students over the year who consistently reported lower levels of teacher support, group work behaviors and opportunities to work cooperatively in small groups, when compared with their older counterparts. Below, we present the findings from the teachers' evaluations of the PLD.

\section{Group work behaviours}

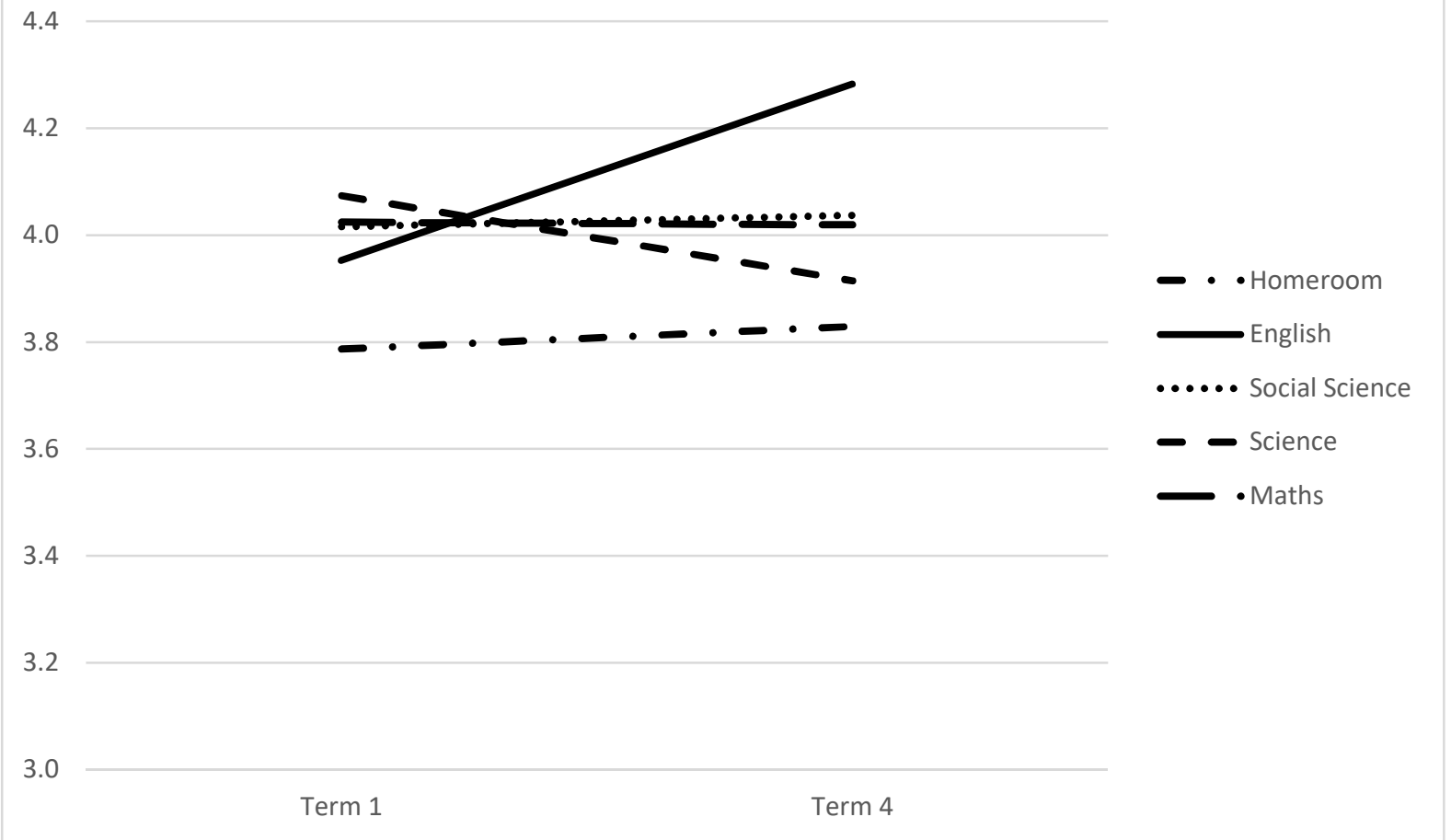

Figure 3. Change in student ratings of their group work behaviors between Terms 1 and 4 and by subject. Note. The y-axis begins at 3.0 and ends at 4.4. Hence, the range of means was small. 


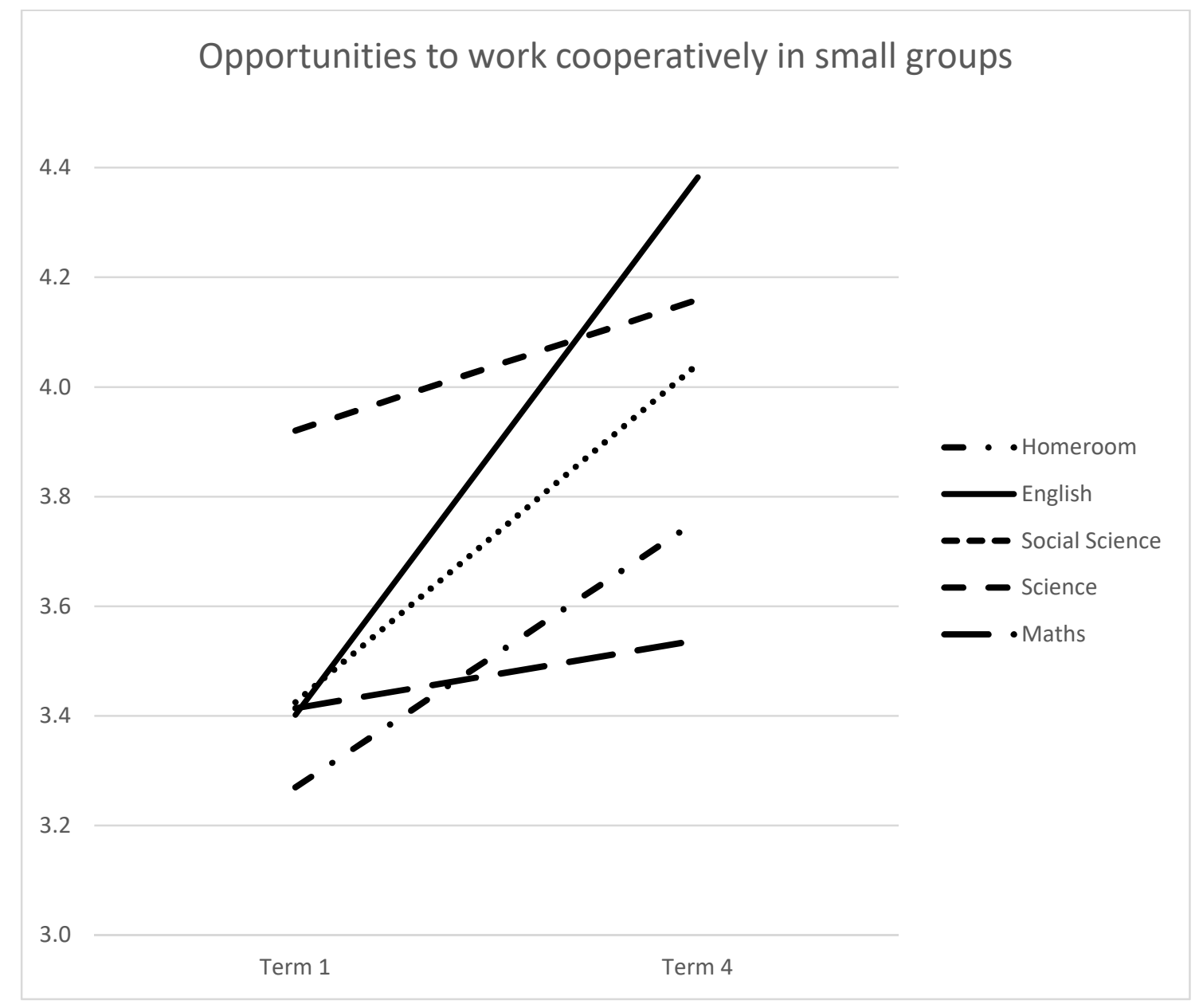

Figure 4. Change in student perceptions of opportunities to work in small groups between Terms 1 and 4 and by subject. Note. The y-axis begins at 3.0 and ends at 4.4. Hence, the range of means was small.

\subsection{Qualitative Data Analysis}

Reflexive thematic analysis [31] involves six phases: familiarization with the data, coding, generating initial themes, reviewing themes, defining and naming themes and writing up. The second author began by reading and re-reading the feedback in order to become thoroughly familiar with the data. Following this, codes were attached to the data. This resulted in the generation of some initial themes. The themes were then checked against the data to ensure that there was fit across the whole dataset. The second author then went back to the dataset to determine the scope and focus of each theme. The results of the analysis are presented below. Once the second author had decided on the themes and the data that pertained to each theme, the first author then checked the assignment of data to themes. There were no disagreements about how the data had been categorized into themes.

Three main themes emerged from the data: what teachers had learned about cooperative grouping as a result of the PLD, the teacher-perceived effects on the students of using cooperative grouping, and what teachers hoped that this would mean for the future. Remembering that the feedback was requested by the school leaders and not the researchers, it was reassuring that no feedback from any teacher was negative. Hence, although all the data below presents a very positive view of the PLD and outcomes for students, that is because it reflects the teacher perceptions. Nevertheless, only eight teachers sent their evaluations to the school leaders, so it is possible that teachers who were less amenable to the PLD and the outcomes for their students did not respond to the request for feedback. 


\subsubsection{Teacher Learning}

Teachers were very positive about the PLD and its perceived benefits:

"I enjoyed the sharing sessions particularly when we were in mixed groups from throughout the school. It was interesting to hear how different teachers approached their collaboration lessons with different age groups throughout the school". (Homeroom teacher)

Another teacher said:

"I have found the cooperative grouping PLD to be both informative and practical. In the lecture portion of the PLD sessions, we were equipped with useful ideas and tools to improve our practice. We were then given time to collaborate in our curriculum teams to create lesson plans and share our own ideas. This was both effective and beneficial, and our curriculum team is putting many of these ideas and practices into place". (Math teacher)

Teachers also reflected on what they had learned. Some teachers indicated that before the PLD, they thought that they knew what cooperative learning was because they used group work at times, for example, "There has been a tendency, prior to the PLD, to do group work and call it cooperative learning. I now have more clarity on what cooperative grouping actually is" (English teacher). Teachers became aware that cooperative grouping involved more than seating students in groups:

"Cooperative grouping requires detailed planning and flexibility which I think is something that can be lost when units have been taught in the same way for the same purpose for a number of years. [The PLD] allowed me to be more reflective". (English teacher)

The PLD appeared to improve the teachers' knowledge of what setting up cooperative groups involved, for example, from one teacher, who often used group work, a very practical consideration, "As a result of the sessions (PLD), I realized some of my group numbers were too large at 5-8, things are working much better with reduced numbers of between 2 and 4." Another teacher reported, "I have now extended my thinking to [how to] include a variety of different curriculum areas [using cooperative grouping] ... Cooperative grouping looks different in different curriculum areas and within different age groups" (Homeroom teacher).

Teachers also recognized the importance of teaching students the social skills needed for cooperative grouping to be effective, "Developing a harmonious class climate is paramount in order for collaboration to take place. Teaching boys to co-operate and be accepting/tolerant of differences is vital" (Homeroom teacher).

A further consideration for teachers was a consideration of time when moving to cooperative grouping:

"[The PLD] has made me slow down and take the time to think about how to implement cooperative grouping. It is a long-term approach, not a one hit wonder. It will get better with time and the results will be worth it". (Homeroom teacher)

\subsubsection{Student Outcomes}

Teachers reported many benefits for the students as a result of implementing cooperative grouping. Some teachers perceived cognitive benefits: "I have noticed that as more [cooperative group] work has been accomplished the boys are picking up the language of cooperation and the discussions are starting to become richer" (English teacher). Another said, "Using cooperative grouping is a wonderful way of setting boys up for success with their learning. It is a great way to develop leadership skills, vocabulary with all [students], but especially with ESOL learners, and confidence with all" (Homeroom teacher). Others noted additional psycho-social advantages, "I think the most important aspect for me is the engagement that the boys are showing." (Science teacher).

However, several teachers noted the importance of training students in cooperative grouping skills before expecting them to work together successfully. Four examples are provided below. In the first one, in a class survey, the students had identified that they wanted to spend more time working in groups: 
"They want to work in groups, and it has been my challenge to ensure they are working as groups. I have enjoyed the cooperative grouping lessons that we have accomplished. It has meant less 'teacher talk' and more student action. Their success or failure at certain tasks has been more down to them engaging in those soft skills that will be so important going forward rather than time management of lessons by me, which makes the learning more meaningful in my view". (English teacher)

Another teacher spoke about the gains in social skills that his students had made since cooperative grouping had been introduced:

"As the boys have got used to the cooperative grouping, they have gone to automatically setting their roles within the groups rather than needing as much teacher prompting. The boys are listening to each other more and making sure everyone in the group is included which has been very encouraging. I have found this has particularly helped with scaffolding within the groups. The boys have more confidence to step up and help each other". (PE teacher)

A further teacher was pleased to report that his Term 3 student survey had identified cooperative grouping as a strength of his teaching. They went on to report:

"Understanding more about roles within groups and how groups collaborate has made the boys more efficient when working in cooperative groups. Time spent learning these skills has been very beneficial in the long run. I feel more confident letting the boys take the lead with their learning due to their ability to work together and set their own goals. It has certainly helped the lower achievers in class raise the standard of what they are producing. The boys are able to give feedback and feedforward in a more honest and sensitive way. There is less conflict around collaborative tasks. Boys seem more comfortable when sharing work with others in the class environment. Seem to be able to work through problems together better, rather than relying on the teacher to sort these out". (Social science teacher)

The final teacher to report on benefits beyond academic gains stated, "They are calmer as they now know they will all get their turn at each role. They are using gentle language to disagree. They have vocabulary to argue constructively" (Homeroom teacher).

\subsubsection{Future Possibilities}

Since teachers saw benefits of the PLD for their teaching as well as for the students' development of soft skills, several wanted the school to build on what had been learned and to continue using cooperative grouping into the future. One teacher said, "I will be looking to include cooperative grouping more next year to complement the explicit teaching that happens now. This has been very worthwhile PLD and should be ongoing in my view" (Science teacher). Another math teacher was already thinking about how to integrate their teaching with aspects of the math curriculum, "Next year, we want to structure our curriculum to directly teach collaborative skills along with problem-solving skills in Term 1." A further teacher spoke more globally about how they believed the school could support their efforts:

"I will look to implement [cooperative grouping] into my planning and I feel it is now important that termly planning includes explicit cooperative grouping teaching and activities. The PLD has been useful and now I would like to see the school look at devising a progression throughout the school and resources and steps for the skills that are to be taught, so that there is clarity and progression to be tracked."

The teachers were overwhelmingly positive about the professional development in cooperative grouping. They reported on what they had learned, what their students had learned and how they had benefited, and expressed a desire to see cooperative grouping maintained within their school. 


\section{Discussion}

The current study sought to explore whether the introduction of whole-school professional development on cooperative learning would be associated with changes in classroom practices, measured by student ratings of teacher support, group work behaviors and opportunities to work cooperatively in small groups, as well as by teacher perceptions of the benefits of the PLD on their practice and students' outcomes. The study also explored whether there were differential outcomes of the PLD by subject or age group, given the existing literature had typically focused on either one curricular area (typically math or science) or age group (typically secondary-aged students). Therefore, this study presented a unique perspective on the differential effects potentially found across curricular areas and age groups, when a whole-school intervention is introduced.

Most importantly, it seemed as though our design of whole-school PLD, rooted in a strong and ongoing partnership with the school, may have led to students experiencing more group work behaviors and cooperation in their classes by the end of the year. Given that the effect sizes reported earlier ranged from small to medium, we posit that positive changes are likely to be emerging at this stage, with teachers' positive feedback suggesting that interventions of this type might require more time before seeing larger effects, as teachers acquire more opportunities to fine-tune their instructional practices around cooperative learning $[7,15]$.

Indeed, we were not surprised to find that student perceptions of teacher support did not increase over time, given these were already high at both the beginning and end of the year. Perhaps, these already-high levels of teacher support were the catalyst for sustained change in practice. Through strong teaching support of students, teachers would have had the opportunity to clearly communicate the goals of each lesson to students and what they were expected to achieve. They would have provided consistent and ongoing scaffolding as students gradually shifted from an individual style of learning and instruction to a more cooperative peer-assisted style of learning. Teachers would have also ensured that students had the appropriate social and group work skills needed to stay on-task and work as groups and not just in groups. This was evident in both the increased levels in perceived group work behaviors reported by students, and by feedback from teachers who articulated the steps required to shift students towards a cooperative style of teaching and learning. Baines and colleagues [12] also point to the importance of training students to work as a group.

Even though we located more studies in the literature that explored the potential benefits of cooperative learning on student outcomes in mathematics and science [23,25], than in other curriculum areas, it was interesting to find that there were no changes evident in ratings of teaching support and opportunities to learn cooperatively in those subjects. Instead, the greatest changes in perceived classroom practices and instruction were in English. On one hand, the qualitative comments by English teachers suggested that they may have been 'early adopters' and supporters of the PLD, which may have translated into greater engagement with the professional development and changes in practice. On the other hand, the science and mathematics departments in the school may have found the change to a more cooperative style of learning and instruction to be particularly challenging. This may have been because these departments used ability grouping in their classes, which is not conducive to implementing cooperative learning strategies in the classroom [12]. Given the mathematics teacher feedback that the PLD was well received by them and potentially their department, it may be that it would take longer than one academic year for change in student ratings to be visible. In future studies, in-depth investigation of the critical enablers (e.g., teacher buy-in and engagement with the PLD) and barriers (e.g., ability grouping) to successful implementation of cooperative learning strategies would help better understand the differential effects of interventions of this kind on student outcomes. Notably, enablers and barriers such as these would not have been possible to pinpoint had this study focused on a single curriculum area. 
Lastly, the finding that cooperative learning practices-and potentially the impact of our PLD on student outcomes-seemed to be more positive for older students in the study is noteworthy. Younger students in the study were taught by a single homeroom teacher who was in charge of all the curriculum areas, whereas older students were taught by different specialist teachers for different subjects. It was possible that specialist teachers found it easier to focus on implementing cooperative learning in their classes, given their emphasis on a single subject or a core curriculum area that they were comfortable teaching. The homeroom teachers would have had to choose a curriculum area first before deciding on when and how to introduce cooperative learning into a lesson. Even though, this reinforces the key message that whole-school interventions may not result in whole-school shifts in attitudes or perceived outcomes, and that care needs to be taken to understand the context and content-specific conditions that would enable teachers to better implement changes in their practice.

\subsection{Limitations and Future Directions}

This study was designed as a natural quasi-experimental design, as the school wanted to partner up to develop a whole-school intervention in cooperative grouping. Nonetheless, this meant that no control group was available to draw conclusions on the effects of the intervention. We caution against generalizing findings from this study to all other school types, given the unique context and demographic breakdown of the school from which the data were analyzed for this study.

As stated earlier, it was not possible to gather comparable and standardized achievement baseline data in this study, which would have allowed us to explore the potential effects of this PLD on students' academic outcomes alongside their psycho-social outcomes. This would have allowed us to triangulate the evidence and compare students' achievement and attitudinal data alongside teachers' feedback. Future studies should also consider developing teacher measures that would enable controls for implementation fidelity and attitudes towards cooperative learning practices, as well as gather feedback from a larger sample of students and teachers. We are aware that only eight teachers were included in the qualitative data, and it is possible that those who were less receptive to the PLD may have chosen not to provide any feedback.

Even though this study has established that our intervention may have had differential outcomes by subject and age group, future studies should also consider exploring whether there could be further differential outcomes by school-level demographics such as school type or resourcing. It is possible that our positive findings may have been because the school we worked with was a well-resourced private school located in a high socio-economic area in New Zealand. We encourage future research to be conducted in schools that may benefit even more from enhancing their learning environments through cooperative learning.

\subsection{Conclusions}

The results of the current study reinforced the potential positive effects of cooperative learning on both classroom practices and teacher perceptions of their learning environment. Whereas previous research had sought to describe the added benefits of cooperative learning in specific curricular areas or with specific groups of students, our study pointed to the need to better understand the enablers and barriers to ensuring that all students could benefit from cooperative grouping. Importantly, though, our study showed that understanding how to translate cooperative learning research into practice, through a one-year university-school partnership, could bring about positive change on classroom practices and outcomes. Our description of how we built the university-school partnership as PLD facilitators, and how we used the student and teacher data to draw conclusions on the potential effects of our approach, showed that PLD opportunities can contribute to changes in instructional practice. We hope that our study will provide a replicable model for future interventions in cooperative grouping. 
Author Contributions: Conceptualization, M.A.; Data curation, C.M.R.-D.; Formal analysis, M.A. and C.M.R.-D.; Investigation, M.A.; Methodology, M.A.; Project administration, M.A.; Writingoriginal draft, M.A.; Writing-review \& editing, C.M.R.-D. All authors have read and agreed to the published version of the manuscript.

Funding: This research received no extra funding.

Institutional Review Board Statement: The study was conducted according to the guidelines of the Declaration of Helsinki, and approved by the Ethics Committee of The University of Auckland.

Informed Consent Statement: Informed consent was obtained from all subjects involved in the study.

Data Availability Statement: Data available on request due to privacy and ethics restrictions.

Conflicts of Interest: The authors declare no conflict of interest.

\section{References}

1. Resnick, L.B. Shared cognition: Thinking as social practice. In Perspectives on Socially Shared Cognition; Resnick, L.B., Levine, J.M., Teasley, S.D., Eds.; American Psychological Association Publishing: Washington, DC, USA, 1991; pp. 1-20. [CrossRef]

2. Baines, E.; Rubie-Davies, C.; Blatchford, P. Improving pupil group work interaction and dialogue in primary classrooms: Results from a year-long intervention study. Camb. J. Educ. 2009, 39, 95-117. [CrossRef]

3. Slavin, R.; Hurley, E.A.; Chamberlain, A. Cooperative learning and achievement: Theory and Research. In Handbook of Psychology, 2nd ed.; Weiner, I.B., Ed.; Wiley: New York, NY, USA, 2003; pp. 177-198. [CrossRef]

4. Gillies, R.M. Cooperative learning: Review of research and practice. Aust. J. Teach. Educ. 2016, 43, 39-54. [CrossRef]

5. Khong, T.D.H.; Saito, E.; Gillies, R.M. Key issues in productive classroom talk and interventions. Educ. Rev. 2019, 71, 334-349. [CrossRef]

6. Rozenszayn, R.; Assaraf, O.B.-Z. When collaborative learning meets nature: Collaborative learning as a meaningful learning tool in the ecology inquiry based project. Res. Sci. Educ. 2011, 41, 123-146. [CrossRef]

7. Blatchford, P.; Baines, E.; Rubie-Davies, C.; Bassett, P.; Chowne, A. The effects of a new approach to group work on pupil-pupil and teacher-pupil interactions. J. Educ. Psychol. 2006, 98, 750-765. [CrossRef]

8. Marcos, R.I.S.; Fernández, V.L.; González, M.T.D.; Phillips-Silver, J. Promoting children's creative thinking through reading and writing in a cooperative learning classroom. Think. Ski. Creat. 2020, 36, 100663. [CrossRef]

9. Davidson, N.; Worsham, T. Enhancing Thinking through Cooperative Learning; Teachers College Press: New York, NY, USA, 1992.

10. Johnson, D.; Johnson, R.; Holubec, E. Cooperation in the Classroom; Allyn and Bacon: Boston, MA, USA, 1998.

11. Kagan, S.; Kagan, M. Kagan Cooperative Learning; Kagan Publishing: San Clemente, CA, USA, 2009.

12. Baines, E.; Blatchford, P.; Kutnick, P. Promoting Effective Group Work in the Primary Classroom: A Handbook for Teachers and Practitioners; Routledge: London, UK, 2017.

13. Gillies, R.M. Promoting academically productive student dialogue during collaborative learning. Int. J. Educ. Res. 2019, 97, 200-209. [CrossRef]

14. Baines, E.; Blatchford, P.; Chowne, A. Improving the effectiveness of collaborative group work in primary schools: Effects on science attainment. Br. Educ. Res. J. 2007, 33, 663-680. [CrossRef]

15. Veenman, S.; Denessesn, E.; van den Akker, A.; van der Rijt, J. Effects of a cooperative learning program on the elaborations of students during help seeking and help giving. Am. Educ. Res. J. 2005, 42, 115-151. [CrossRef]

16. Johnson, D.; Maruyama, G.; Johnson, R.; Nelson, D.; Skon, L. Effects of cooperative, competitive, and individualistic goal structures on achievement: A meta analysis. Psychol. Bull. 1981, 89, 47-62. [CrossRef]

17. Johnson, D.; Johnson, R. Learning Together and Alone, 4th ed.; Allyn \& Bacon: Boston, MA, USA, 1994.

18. Roseth, C.; Johnson, D.; Johnson, R. Promoting early adolescents' achievement and peer relationships: The effects of cooperative, competitive, and individualistic goal structures. Psychol. Bull. 2008, 134, 223-246. [CrossRef]

19. Slavin, R. Cooperative learning and student achievement. In School and Classroom Organization; Slavin, R., Ed.; Lawrence Erlbaum: Mahwah, NJ, USA, 1989; pp. 129-156.

20. Johnson, D.; Johnson, R. Learning together and alone: Overview and meta-analysis. Asia Pac. J. Educ. 2002, 22, 95-105. [CrossRef]

21. Carroll, A.; Gillies, R.M.; Cunnington, R.; McCarthy, M.; Sherwell, C.; Palghat, K.; Goh, F.; Baffour, B.; Bourgeois, A.; Rafter, M.; et al. Changes in science attitudes, beliefs, knowledge and physiological arousal after implementation of a multimodal, cooperative intervention in primary science school classes. Inf. Learn. Sci. 2019, 120, 409-425. [CrossRef]

22. Chinn, C.A.; O’Donnell, A.M.; Jinks, T.S. The structure of discourse in collaborative learning. J. Exp. Educ. 2000, 69, 77-97. [CrossRef]

23. Gillies, R.M. Dialogic teaching during cooperative inquiry-based science: A case study of a Year 6 classroom. Educ. Sci. 2020, 10, 328. [CrossRef]

24. Scott, P.; Mortimer, E.; Aguiar, O. The tension between authoritative and dialogic discourse: A fundamental characteristic of meaning making interactions in high school science lessons. Sci. Educ. 2006, 90, 605-631. [CrossRef] 
25. Resnick, L.; Michaels, S.; O'Connor, C. How (well structured) talk builds the mind. In Innovations in Educational Psychology: Perspectives on Learning, Teaching and Human Development; Pressis, D., Sternberg, R., Eds.; Springer: New York, NY, USA, 2010; pp. 163-194.

26. Seymour, J.; Lehrer, R. Tracing the evolution of pedagogical content knowledge as the development of interanimated discourses. J. Learn. Sci. 2006, 15, 549-582. [CrossRef]

27. Webb, N.; Franke, M.; Ing, M.; Wong, J.; Fernandez, C.H.; Shin, N.; Turrou, A.C. Engaging with others' mathematical ideas: Interrelationships among student participation, teachers' instructional practices, and learning. Int. J. Educ. Res. 2014, 63, 79-93. [CrossRef]

28. Wanzek, J.; Kent, S.C.; Vaughn, S.; Swanson, E.A.; Roberts, G.; Haynes, M. Implementing team-based learning in middle school social studies classes. J. Educ. Res. 2015, 108, 331-344. [CrossRef]

29. Lou, Y.; Abrami, P.C.; Spence, J.C.; Poulsen, C.; Chambers, B.; d'Apollonia, S. Within-class grouping: A meta-analysis. Rev. Educ. Res. 2004, 66, 423-458. [CrossRef]

30. Pallant, J. SPSS Survival Manual: A Step by Step Guide to Data Analysis Using IBM SPSS; Routledge: London, UK, 2020.

31. Clarke, V.; Braun, V.; Terry, G.; Hayfield, N. Thematic analysis. In Handbook of Research Methods in Health and Social Sciences; Liamputtong, P., Ed.; Springer: New York, NY, USA, 2019; pp. 843-860.

32. Brown, T.A. Confirmatory Factor Analysis for Applied Research; Guilford Publications Inc.: New York, NY, USA, 2015.

33. Hu, L.; Bentler, P. Cutoff criteria for fit indexes in covariance structure analysis: Conventional criteria versus new alternatives. Struct. Equ. Model. Multidiscip. J. 1999, 6, 1-55. [CrossRef]

34. Byrne, B.M.; Shavelson, R.J.; Muthen, B. Testing for the equivalence of factor covariance and mean structures: The issue of partial measurement invariance. Psychol. Bull. 1989, 105, 456-466. [CrossRef]

35. Cheung, G.W.; Rensvold, R.B. Evaluating goodness-of-fit indexes for testing measurement invariance. Struct. Equ. Model. 2002, 9 , 233-255. [CrossRef]

36. Milfont, T.; Fischer, R. Testing measurement invariance across groups: Applications in cross-cultural research. Int. J. Psychol. Res. 2010, 3, 111-121. [CrossRef] 